\title{
Polysilsesquioxanes Through Base-Catalyzed Redistribution of Oligohydridosiloxanes
}

Kamyar Rahimian ${ }^{1}$, Roger A. Assink ${ }^{1}$, David P. Lang ${ }^{1}$, Douglas A. Loy ${ }^{*^{2}}$

${ }^{1}$ Organic Materials Department, Sandia National Laboratories, Albuquerque, NM 87185-1407

${ }^{2}$ Catalysis and Chemical Technologies Department, Sandia National Laboratories, Albuquerque, NM 87185-1407

\section{INTRODUCTION}

Organopolysilsesquioxanes have recently gained much interest as materials for low-K dielectrics [1], ceramic precursors [2] and photoresists [3]. Typical sol-gel synthesis of polysilsesquioxanes involves the hydrolysis of organotricholorosilanes and/or organotrialkoxysilanes in the presence of acid or base catalysts and organic solvents. However, under sol-gel conditions most organotrialkoxysilanes do not afford silsesquioxane gels. This limits the range of organic functionalities that can be introduced into these hybrid organicinorganic materials.

An alternative route to polysilsesquioxanes is through oligohydridosiloxanes. Catalytic disproportionation, by titanium complexes, of linear or cyclic oligomers of methylhydridosiloxanes can lead to polymethylsilsesquioxanes [4]. We have shown that disproportionation of oligomethylhydridosiloxanes can also be catalyzed by tetrabutylammonium hydroxide to yield polymethylsilsesquioxanes (scheme 1) [5]. This replaces the step-growth solgel polymerization process of organotrialkoxysilanes, which requires solvent, stoichiometric water and produces alcohol and water condensation by-products. Tetraalkylammonium hydroxides, as catalysts, are also attractive because they readily decompose by heating above $150{ }^{\circ} \mathrm{C}$; thus, they can be easily removed from the final materials.

\section{Scheme 1}

$$
-\left[\mathrm{MeHSiO}_{\mathrm{n}^{-}} \stackrel{\mathrm{Bu}_{4} \mathrm{NOH}}{\longrightarrow} 0.33 \mathrm{n} \mathrm{MeSiH}_{3}+-\left[\mathrm{MeSiO}_{1.5}\right]_{\mathrm{n}^{-}}\right.
$$

In this paper we report on both the catalytic and stoichiometric redistribution of organohydridosiloxanes to produce polysilsesquioxane foams and gels of the formula $\left(\mathrm{RSiO}_{1.5}\right)_{\mathrm{n}}$, which otherwise cannot be obtained through traditional sol-gel means.

\section{EXPERIMENTAL DETAILS}

Oligohydridosiloxanes, $[\mathrm{RHSiO}]_{\mathrm{n}}(\mathrm{R}=\mathrm{Me}, \mathrm{Et}, \mathrm{Ph})$ and $[\mathrm{MeHSiO}]_{\mathrm{n}}\left[\mathrm{Me}_{2} \mathrm{SiO}\right]_{\mathrm{n}}$ were purchased from Gelest and used as received. In a typical reaction, the oligohydridosiloxane was weighed out in a flask and catalytic amounts of tetrabutylammonium hydroxide (TBAH) $(0.1 \mathrm{~N}$ solution in $\mathrm{MeOH}$ /toluene, purchased from Acros and used as received) were added. The reaction, performed both under argon atmosphere and repeated in air, is exothermic and immediate generation of $\mathrm{RSiH}_{3}$ was observed; for $\mathrm{R}=\mathrm{Me}, \mathrm{Et}$, the silane is gaseous and is released from the reaction. For $\mathrm{R}=\mathrm{Me}, \mathrm{Et}$, as more $\mathrm{RSiH}_{3}$ is generated, the product gets more viscous, and within one minute the reaction solidifies. For $\mathrm{R}=\mathrm{Ph}, \mathrm{PhSiH}_{3}$ is not isolated from 


\section{DISCLAIMER}

This report was prepared as an account of work sponsored by an agency of the United States Government. Neither the United States Government nor any agency thereof, nor any of their employees, make any warranty, express or implied, or assumes any legal liability or responsibility for the accuracy, completeness, or usefulness of any information, apparatus, product, or process disclosed, or represents that its use would not infringe privately owned rights. Reference herein to any specific commercial product, process, or service by trade name, trademark, manufacturer, or otherwise does not necessarily constitute or imply its endorsement, recommendation, or favoring by the United States Government or any agency thereof. The views and opinions of authors expressed herein do not necessarily state or reflect those of the United States Government or any agency thereof. 


\section{DISCLAIMER}

Portions of this document may be illegible in electronic image products. Images are produced from the best available original document. 
the reaction and becomes part of the final product. The resulting gels were analyzed by IR and solid state NMR spectroscopy.

Reactions which are performed in THF are as follows: The oligohydridosiloxane is placed in a $100 \mathrm{~mL}$ round bottom flask and diluted with $60 \mathrm{~mL}$ of THF. TBAH is slowly added to the reaction via syringe, the reaction is stirred overnight ( $\sim 12$ hours) and the volatiles are removed in vacuo ( 0.01 Torr). The final product is analyzed by IR and NMR spectroscopy.

Caution: At high catalyst concentrations $(1.00 \mathrm{~mol} \%)$, the reaction is very exothermic, violent and can erupt out of the reaction vessel.

\section{RESULTS AND DISCUSSION}

Methylhydridosiloxanes. The general scheme for the reactions of PMHS with TBAH is shown in Scheme 1. The reaction is exothermic and very rapid. As the amount of TBAH catalyst is increased, so do the exothermicity of the reaction and the rate of the reaction. The reaction solidifies within one minute of $\mathrm{TBAH}$ addition. $\mathrm{As} \mathrm{MeSiH}_{3}$ gas is produced during the reaction (confirmed by ${ }^{\mathrm{H}} \mathrm{H}$ NMR spectroscopy of the gas evolved), the resulting material foams under neat conditions and can discharge out of the reaction vessel. Figure 1 shows a picture of a typical reaction of PMHS with catalytic amounts of TBAH, under neat conditions. Under these conditions not all of the $\mathrm{SiH}$ groups can be converted to $\mathrm{MeSiH}_{3}$, as the reaction is so rapid that it solidifies before the redistribution reaction has a chance to reach completion. This is demonstrated by solid state NMR spectroscopy (Figure 2), which reflects conversion to silsesquioxane silicons of approximately $75 \%$.

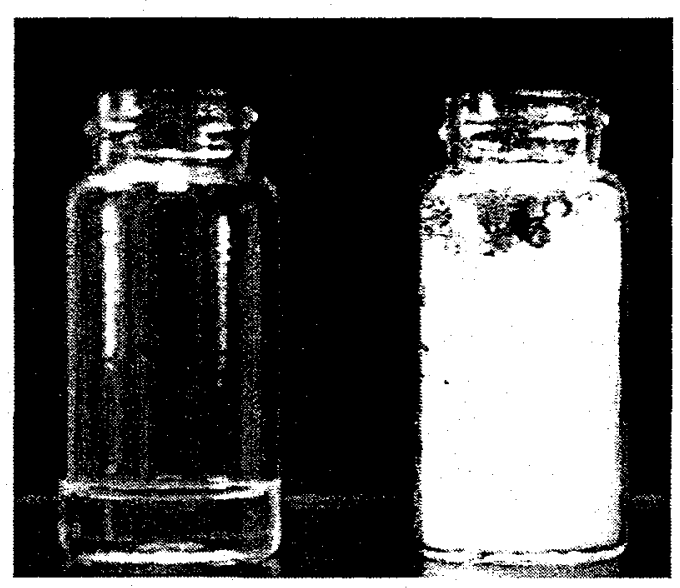

Figure 1. Picture of the starting PMHS (left vial) and the resulting foam from the reaction of the same amount of PMHS $(3.00 \mathrm{~g})$ with catalytic TBAH $(150 \mu \mathrm{L})$. 




Figure 2. Solid state ${ }^{29} \mathrm{Si} N \mathrm{NR}$ spectra of reaction of neat PMHS with catalytic amounts of TBAH: 0.024 mol\% TBAH (bottom spectrum); 0.24 mol\% (middle spectrum); 1.20 mol\% (top spectrum).

The reaction can be driven to completion when performed in a solvent, such as THF, and under dilute conditions $(0.012 \mathrm{M}$ solution in THF, $2.0 \mathrm{~mol} \% \mathrm{TBAH}$ based on repeating units-r.u.of the starting oligomer) and the mixture is allowed to react longer periods (ovemight). Still,at higher concentrations ( $0.30 \mathrm{M}$ in THF based on r.u.), upon addition of the TBAH catalyst (1.0 mol\% TBAH based on r.u.) the solution gels and the reaction does not reach completion. As more TBAH is used in the reaction, a small resonance, attributed to $\mathrm{T}^{2}$ silsesquioxane silicons $\left[\mathrm{RSiO}_{2}(\mathrm{OH})\right]$, appears in the NMR spectrum (Figure 3, bottom spectrum). This species is much more prominent when excess TBAH is used in the reaction (Figure 3, top spectrum).

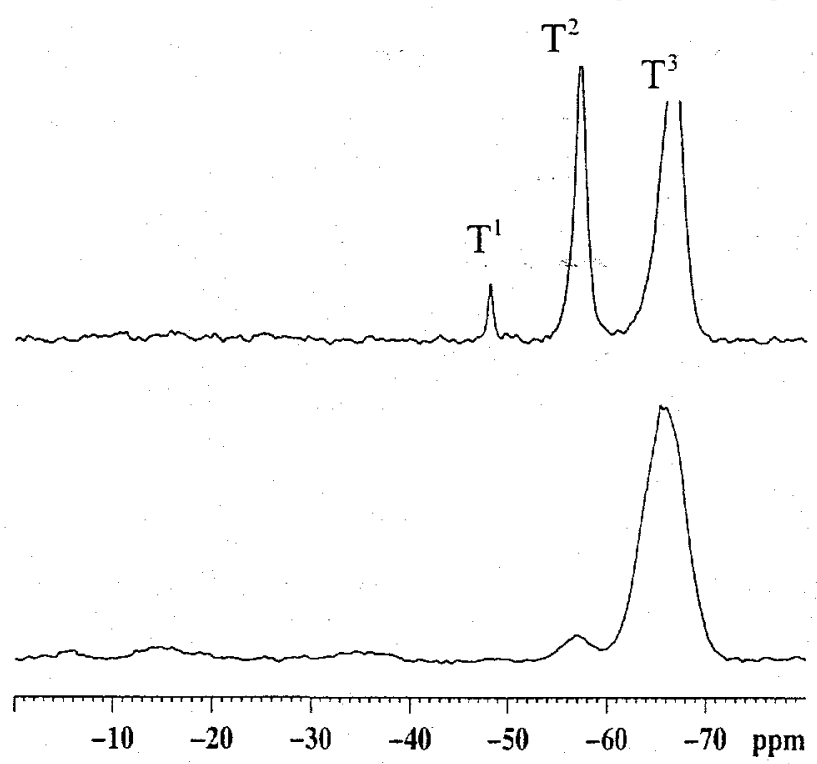

Figure 3. Solid state ${ }^{29}$ Si NMR spectra of reaction of PMHS, in THF, with TBAH: catalytic TBAH (left spectrum); excess TBAH (right spectrum). 
Based on the above observations, a possible mechanism for the redistribution reaction of PMHS with TBAH is proposed in Scheme 2. Intermediate (a) would produce $\mathrm{MeSiH}_{3}$, which has been confirmed independently by ${ }^{1} \mathrm{H}$ NMR spectroscopy by isolating the volatiles from the redistribution reaction. The silanoate intermediate (b) would result in the formation of $\mathrm{T}^{3}$ silsesquioxane Si's, the dominant species when catalytic amounts of TBAH are used. Use of excess TBAH generates more of $\mathrm{T}^{2}$ silicon species (c), which is confirmed by NMR spectroscopy (Figure 3, top spectrum). An important note to these reactions is that although the catalytic redristribution of alkoxysilanes, $(\mathrm{RO})_{3} \mathrm{SiH}$, with nucleophilic catalysts or TBAH produces hydrogen gas $[6,7]$, no hydrogen was observed in the above reactions.

Scheme 2. Proposed mechanism for the redistribution reaction of PMHA with TBAH.

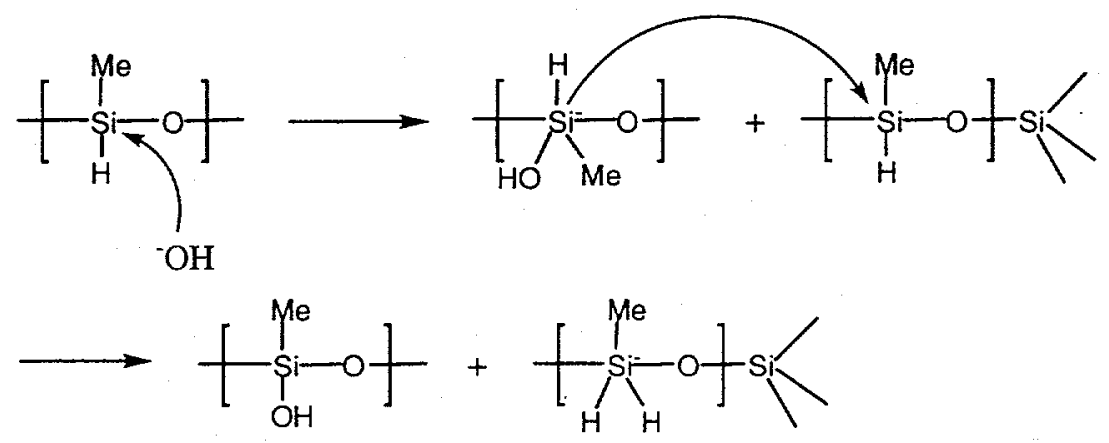

(c)

$\mathrm{T}^{2}$ silicons

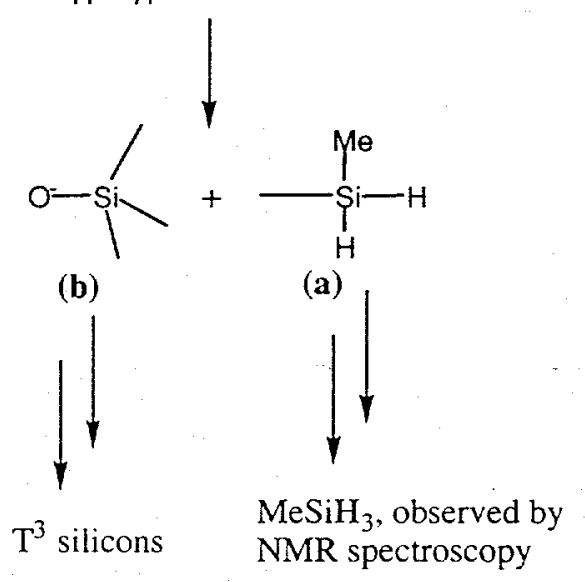

Ethyl and Phenylhydridosiloxanes. Under sol-gel conditions, ethyltrialkoxysilanes produce gels only under very specific conditions, high concentration, basic conditions and long reaction times; phenyltrialkoxysilanes do not produce gels at all. The redistribution reaction of oligoethyl- and oligophenylhydridosiloxanes follows the same reaction pathway as that of methylhydridosiloxanes (Scheme 3). Again, the extent of the redistribution reaction can be controlled by changing the reaction conditions (Figure 4,5 ). When $\mathrm{R}=\mathrm{Ph}$, the resulting silane $\left(\mathrm{PhSiH}_{3}\right)$ is not volatile, and if left in the reaction mixture it will react and become part of the final silsesquioxane product, as confirmed by NMR spectroscopy (Figure 5). 
Scheme 3. Reaction scheme for redistribution reaction of $\mathrm{P}(\mathrm{R}) \mathrm{HS}(\mathrm{R}=\mathrm{Et}, \mathrm{Ph})$ with $\mathrm{TBAH}$.
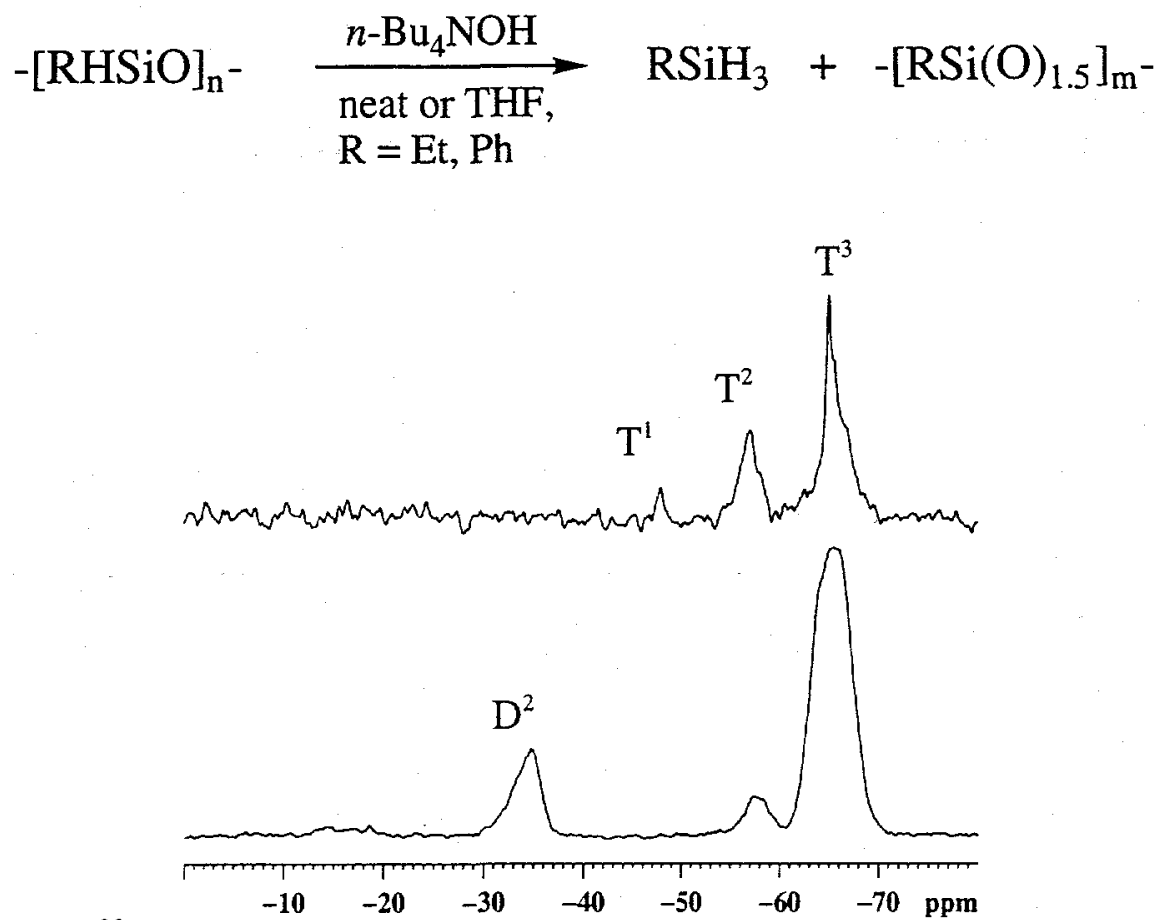

Figure 4. Solid state ${ }^{29} \mathrm{Si}$ NMR spectra of redistribution reaction of PEtHS with TBAH: Bottom spectrum, catalytic TBAH and neat conditions; top spectrum, catalytic TBAH and in THF solvent.

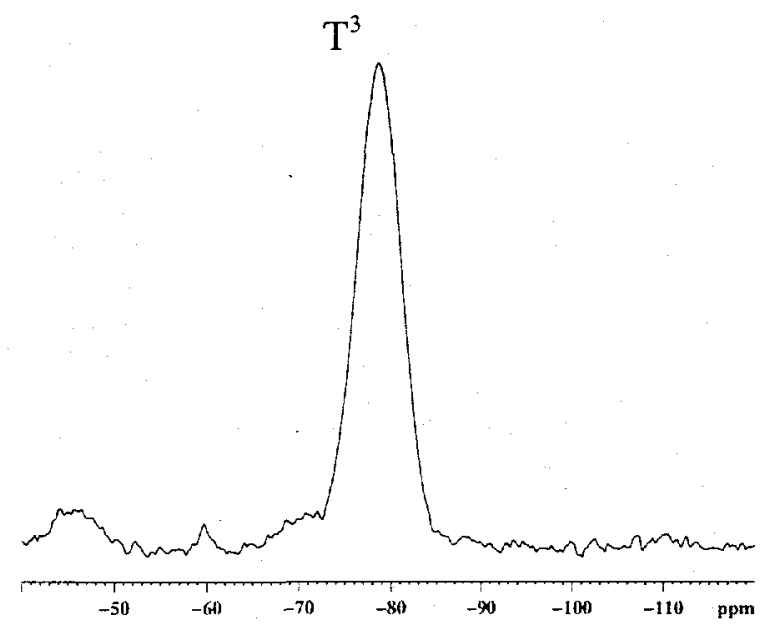

Figure 5. Solid state ${ }^{29}$ Si NMR spectrum of redistribution reaction of PPhHS with catalytic $T B A H$, under neat conditions.

Methylhydridosiloxane-dimethylsiloxane copolymers. Catalytic redistribution reaction of PMHS/PDMS copolymer follows the same pathway and displays the same trend as the PMHS reactions. As the amount of TBAH catalyst is increased, more $\mathrm{MeSiH}_{3}$ is produced; also, all of the $\mathrm{SiH}$ portion of the copolymers can be converted when the reaction is performed in solvent and allowed to reach completion, or when sufficient catalyst is added (Figure 3 ). The linearity content in the final product can be varied by simply varying the amount of the PDMS portion of 
the starting oligomer. This methodology provides easy access to silsesquioxane polymers which can not be accessed by other means.

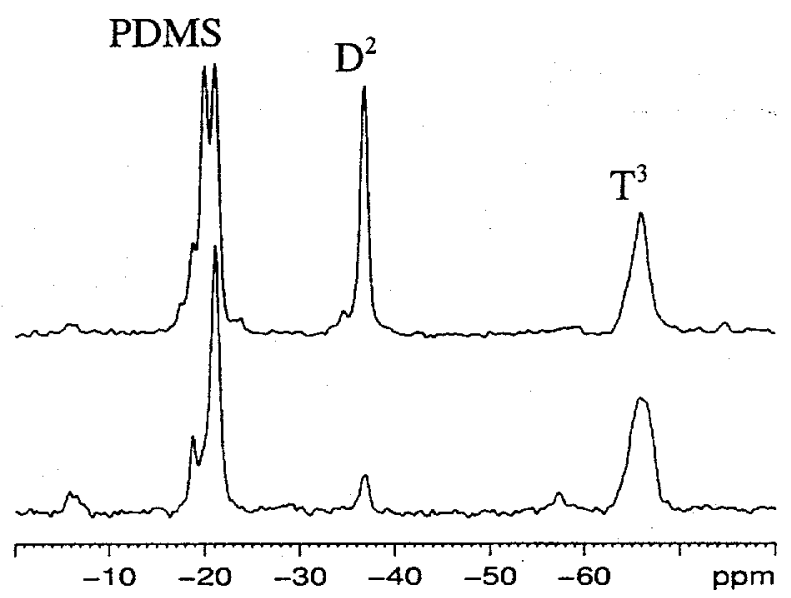

Figure 6. Solid state ${ }^{29}$ Si NMR spectra of the products of catalytic reaction of PMHS/PDMS oligomerr (50-55\% PMHS) with TBAH: Bottom spectrum, neat oligomer with 0.04 mol\% TBAH; top spectrum, neat oligomer with 4.0 mol\% TBAH (values based on "MeHSiO" repeating unit).

\section{CONCLUSIONS}

Oligohydridosiloxanes undergo redistribution chemistry with catalytic tetrabutylammonium hydroxide to produce methylsilane and polysilsesquioxanes. The rate and extent of the redistribution reaction can be controlled by the amount of TBAH added, as well as use of solvent. The extent of reaction can be followed by both IR and solid state NMR spectroscopy, following the disappearance of the $\mathrm{SiH}$ in the starting oligosiloxane. The same methodology can be used to synthesize copolymers of methylsilsesquioxane and dimethylsiloxane. The redistribution chemistry gives easy access to silsesquioxane foams and gels which cannot be easily synthesized, if at all, through traditional sol-gel means.

ACKNOWLEDGEMENT. We would like to thank Arturo Sanchez (IR spectroscopy) for assistance. Sandia is a multiprogram laboratory operated by Sandia Corporation, a Lockheed Martin Company, for the United States Department of Energy under Contract DE-AC0494AL85000.

\section{REFERENCES}

(1) K.R. Carter, P. T. Furuta, C. T. Hawker, et. al., Polym. Mater. Sci. Eng., 81, 67 (1999).

(2) N. Takamura, K. Taguchi, T. gunji, Y. Abe, J. Sol-Gel Sci. Technol., 16, 227 (1999).

(3) J. Hatakeyama, M. Nakashima, et. al., Proc. SPIE-Int. Soc. Opt. Eng., 3333, 62 (1998).

(4) (a) J. F. Harrod, S. Xin, C. Aitken, Y. Mu, E. Samuel, Can. J. chem., 68, 471 (1990). (b) R. M. Laine, J. A. Rahn, K. A. Youngdahl, F. Babonneau, M. L. Hoppe, Z.-F. Zhang, J. F. Harrod, Chem. Mater., 2, 464 (1990).

(5) K. Rahimian, D. A. Loy, Polymer Preprints, 41 (1), 512 (2000).

(6) R. P. J. Corriu, R. Perz, C. Reye, Tetrahedron, 39, 999 (1983).

(7) D. A. Loy, D. A. Schneider, Manuscript in preparation. 